http://zoobank.org/urn:lsid:zoobank.org:act:57EA8276-B691-4274-BF30-11DC1F297DB8; http://zoobank.org/urn:lsid:zoobank.org:act:D6591DB9-5702-4EEF-9DC9-26DC54937F2

\title{
CALLIDIOPINI BEETLES (COLEOPTERA, CERAMBYCIDAE) IN THE COLLECTION OF MUSEUM ZOOLOGICUM BOGORIENSE, INDONESIA. PART II. GENITALIA AND TAXONOMY OF THE GENUS TETHIONEA PASCOE
}

\author{
Yaheita Yokoi**1, Hiroshi Makihara ${ }^{2}$, and Woro A. Noerdjito ${ }^{3}$ \\ ${ }^{1}$ Beerenkothen 33, 40882 Ratingen, Germany \\ ${ }^{2}$ Forestry and Forest Products Research Institute (FFPRI), 1 Matsunosato, Tsukuba, \\ Ibaraki, 395-8687, Japan \\ ${ }^{3}$ Museum Zoologicum Bogoriense, Research Center for Biology, National Research and Innovation Agency \\ (BRIN) Jl. Raya Jakarta-Bogor Km 46, Cibinong, Bogor 16911, Indonesia \\ *Corresponding author: y.yokoi@kddnet.de
}

Received: 21 May 2021; Accepted: 10 December 2021; Published: 30 December 2021

\begin{abstract}
Species of Tethionea Pascoe, 1869, Callidiopini, in the collection of Museum of Zoologicum Bogoriense are reviewed. Two new species of the genus are described, $T$. peggieae sp. nov. and $T$. oculata sp. nov., both from Papua Province, Indonesia. In addition, T. unicolor Pascoe, T. strumosa Pascoe and T. tridentata Pascoe are redescribed. Their male genitalia are documented and illustrated in detail. In particular, the ejaculatory duct complexes of endophalli are carefully observed, as well as $8^{\text {th }}$ sternites and tergites. For T. oculata sp. nov., the female genitalia are described. Morphological and taxonomical aspects of these species are discussed.
\end{abstract}

Key words: Callidiopini, ejaculatory duct complex, endophallus, genitalia, Tethionea

\section{INTRODUCTION}

In our previous publication, some Callidiopini species in the collection of the Museum of Zoologicum Bogoriense (MZB), Cibinong, Indonesia, were reviewed. Four new species of Ceresium or Examnes were described, and their male genital organs were documented and illustrated in detail (Yokoi et al., 2019).

In this study, we review the species of Tethionea. The genus includes hitherto 24 species, mostly recorded from the Australian Region. It was first introduced by Pascoe, who described four species from the "Moluccas" (Pascoe, 1862, 1869; now generally known as Maluku). In the last century, one new species was described from New Caledonia (Fauvel, 1906), and 12 species and one subspecies were described from New Guinea (Gressitt, 1951, 1955, 1959). Gressitt redescribed Tethionea, providing a diagnostic key for the species. In recent years, 6 new species have been described; one each from the Malay Peninsula, Java, Lombok and Borneo, and two species from the Philippines (Hayashi, 1979; Yokoi, 2015; Holzschuh, 2015; Vives, 2015, 2016). More recently, the genus was redescribed based on species from Australia (Ślipiński \& Escalona, 2016). Tethionea was compared to Ceresium by Pascoe and Gressitt. For further consideration of the taxonomy, however, a more advanced material basis is required. Additional species should be explored and closely examined. In the following, two new species are described and three known species redescribed. 
For the taxonomy of the Callidiopini, it is important to investigate male genitalia because these provide definitive diagnoses for the species and also indicate relationships with other genera. Particularly important are the ejaculatory duct complexes and the $8^{\text {th }}$ sternite. In recent years, male genitalia of Ceresium Newman, 1842, Oxymagis Pascoe, 1866, Examnes Pascoe, 1869, Stenodryas Bates, 1873, and Falsoibidion Pic, 1923, were described (Yokoi, 2019, 2021a, 2021b; 2021 in press; Yokoi et al., 2016, 2019). In contrast, the knowledge of genitalia of Tethionea is still very limited. In recent years, male genitalia of Tethionea lassehubweberi Yokoi were partly described (Yokoi, 2015). Moreover, the male genitalia were included in the above noted description of the Australian Tethionea species by Ślipiński and Escalona. Nevertheless, altogether only a small number of Tethionea species have been examined. Therefore, male genitalia of three known species, Tethionea unicolor Pascoe, Tethionea strumosa Pascoe and Tethionea tridentata Pascoe are described below, together with those of the new species Tethionea peggieae sp. nov. In addition, female genitalia of Tethionea oculata sp. nov. are described.

Other interesting aspects of Tethionea morphology were also observed. As the venters were not included in the original descriptions of the above three known species, they were investigated anew. Regarding the structure of their maxillary palpi, Pascoe discovered interesting variations, and Gressitt later made a comprehensive observation. Maxillary palpi were re-examined for this publication. Finally, future prospect of the research is outlined in DISCUSSION.

\section{MATERIALS AND METHODS}

The method remains basically the same as in our previous publication (Yokoi et al., 2019). The material was provided by the collection of MZB. The specimens thereof were mostly collected in various parts of Indonesia under the auspices of the Indonesian Institute of Science (LIPI). Additionally, specimens collected by the second author in Papua New Guinea are included in the collection. The holotypes and a paratype designated herein will be preserved in MZB.

The abbreviations used for the ratio of the measurement in the descriptions are as follows: BLe- body length measured from apical margin of clypeus to elytral apices; HWhead width across eyes, PL- length of pronotum, PW- maximum width of pronotum, PAapical width of pronotum, PB- basal width of pronotum, EL- length of elytra, EW- humeral width of elytra.

In this publication, the sclerotized complex of apical endophallus is referred to as "ejaculatory duct complex", as in the previous publication. The side or direction to which the ejaculatory duct is attached or pointed is referred to as "dorsal "or "apical". 


\section{RESULTS}

As a result of the above investigation, we describe two new species of the genus Tethionea from Irian Jaya, New Guinea. Tethionea peggieae sp. nov. is comparable to a few known species, while Tethionea oculata sp. nov. is rather singular in appearance.

In the course of the recent observation, the importance of male genitalia for taxonomy was again underlined. Above all, it was revealed that Tethionea essentially shares the similar type of endophallus with Ceresium, Examnes, Stenodryas and Oxymagis, four affiliated genera of the same tribe. These results are described below in "Taxonomy". Further, morphological and taxonomical aspects beyond the description of individual species are treated in DISCUSSION. The genitalia, prosternal processes and maxillary palpi of the examined species are discussed there.

\section{Taxonomy}

Tethionea peggieae sp. nov.

(Figs 1A-E; 2A-L)

Material examined. Holotype $\delta$ : "INDONESIA, Irian Jaya, Freeport Concession Timika. 12 -19.IX. 1997, R. Ubaidillah, Peggie, 97032”; "Pandans peat swamp, East levee of Minajerwi river. 4. 4099'S. 136.5854'W. 15 m. Malaise trap-1(Site 4)”;“"7701”.

Diagnosis. Pronotum elongated. Pronotal sides uneven; densely, deeply punctate-verrucose. Prosternum densely, deeply punctate-scabrous. Prosternal process narrow, apically feebly expanded. Elytral apices each terminated with an acuminate spine. Legs stout, femora keeled. Upper eye-lobes widely separated from each other.

Etymology. The name of this new species is dedicated to Dr. Djunijanti Peggie, the butterfly curator of Museum Zoologicum Bogoriense, who collected the specimen.

\section{Description.}

Measurements. BLe=8.5mm. $\mathrm{EL} / \mathrm{EW}=2.80 . \quad \mathrm{HW} / \mathrm{PW}=0.84 . \mathrm{PL} / \mathrm{PW}=1.15 . \quad \mathrm{PA} / \mathrm{PW}=0.74 . \mathrm{PB} /$ $\mathrm{PW}=0.96$.

Color testaceus; antennae and legs paler; setae yellowish.

Head evenly, moderately punctate, nearly hairless. Frons transverse-sub-rectangular, horizontally impressed near apex, with a feeble median groove. The terminal joints of maxillary palpi spatulate, with external sides moderately truncated and opened (Fig. 11F). Vertex broad, widely flattened, hardly concave. Upper eye-lobes narrow, separated from each other by $5 / 2$ the width of lobe or $2 / 5$ the width of occiput. Antennal supports flattened. Antennae reaching the elytral apices with the last articles. Scape stout, clavate, weakly 
arcuate, coarsely punctured. Antennomeres 3 and 4 a little shorter than scape; 5 and 6 about 6/5 as long as scape; 7-11 gradually attenuated.

Pronotum longer than broad, glossy, almost hairless; apex strongly and base moderately constricted; disc flattened, regularly punctured, with an impunctate median stripe $2 / 5$ the length of pronotum; sides arcuate, uneven with irregular costae, densely and deeply punctate -verrucose. Scutellum sub-circular.

Elytra each weakly tapering toward apex; terminated by an acuminate spine. The external side of the spine emarginated; the sutural side weakly so. Basal 3/4 of elytra evenly, moderately punctured; hairless. Apical 1/4 with smaller, shallower punctures, some of which are setiferous, each bearing a sub-erect setae of medium length.

Legs rather short and stout. Femora strongly clavate from base on; ventrally keeled (Fig. $1 \mathrm{E})$.

Venter. Prosternum convex; glossy; deeply, densely punctate-scabrous, with several hairs in the middle. Prosternal process narrow; apex feebly expanded, truncated. Mesoventrite nearly hairless, with sparse though large, deep punctures; moderately elevated toward the process. Mesoventral process with several large setiferous punctures; base broad; apically sub-parallel-sided; apex deeply emarginated in the middle. Metaventrite transverse-subrectangular, convex; glossy, regularly provided with sparse though large punctures, which are more or less setiferous in the middle.

Abdomen gradually narrowed toward apex; sternites $4-7$ about $4 / 5$ as long as the third; glossy; with sparse setiferous punctures.

Male genitalia as Figs 2A-L. Median lobe about 2/5 the length of abdomen; fusiform in dorsal view; thick and strongly arcuate in lateral view; dorsal plate dehiscent in the basal half; ventral plate a little longer and narrower than the dorsal, dehiscent in basal $2 / 3$. Tegmen about 4/5 the length of median lobe, arcuate in lateral view. Parameres about 9/20 the length of tegmen; basal half distinctly and apical half feebly tapering toward apex; apical 1/4 bilobed; each lobe with several short, stout apical setae. Ejaculatory duct complex as Figs $2 \mathrm{G}-$ I; about half as long as median lobe; slender, composed of three inter-connected sclerites; apical sclerite composed of two elongated rod-like structures; median sclerite stout, with a prominent horn-shaped projection; basal sclerite elongated, flattened, apically dehiscent. $8^{\text {th }}$ sternite in gingko-leave-form; blade widely thinned in the middle, with several apical setae; peduncle a little shorter than blade. $8^{\text {th }}$ tergite truncated on apex; apical $2 / 3$ sub-congruent with $8^{\text {th }}$ sternite; apical setae similar to those of the sternite.

Distribution. Papua Province, Indonesia (New Guinea). 


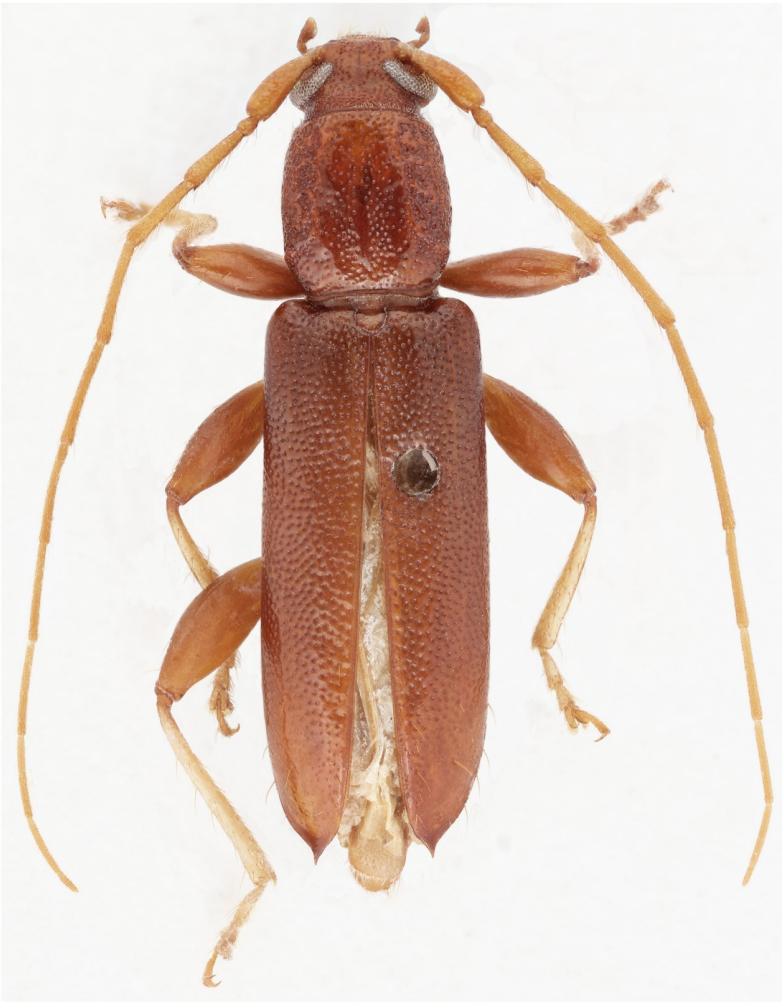

$1 \mathrm{~A}$

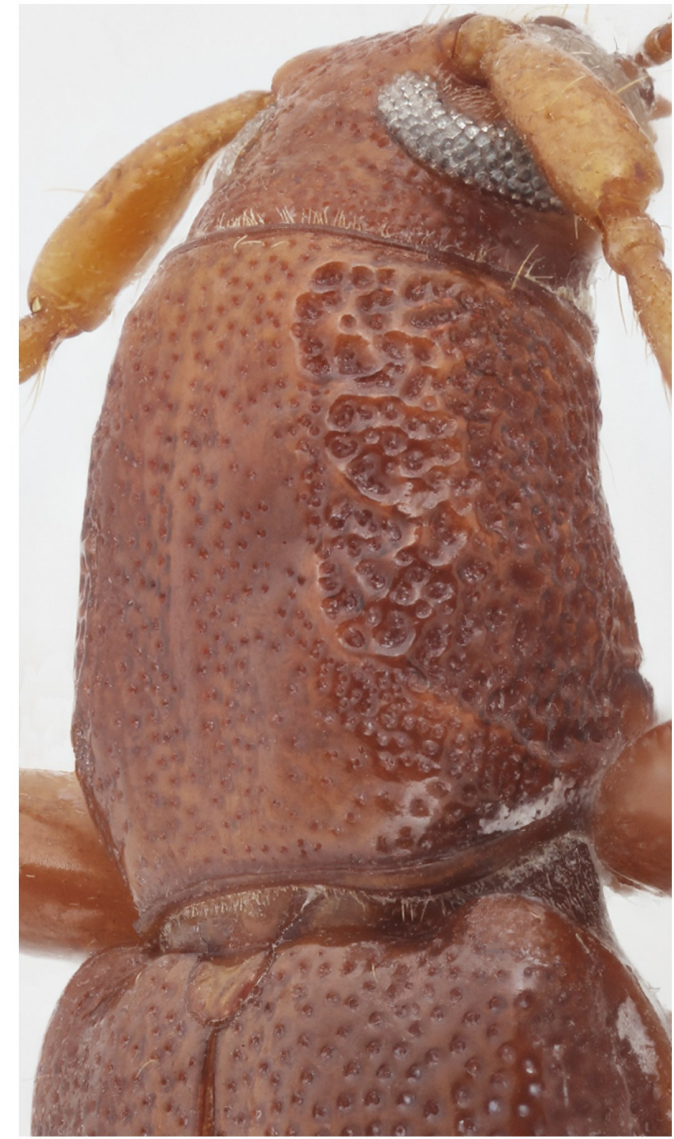

$1 \mathrm{C}$
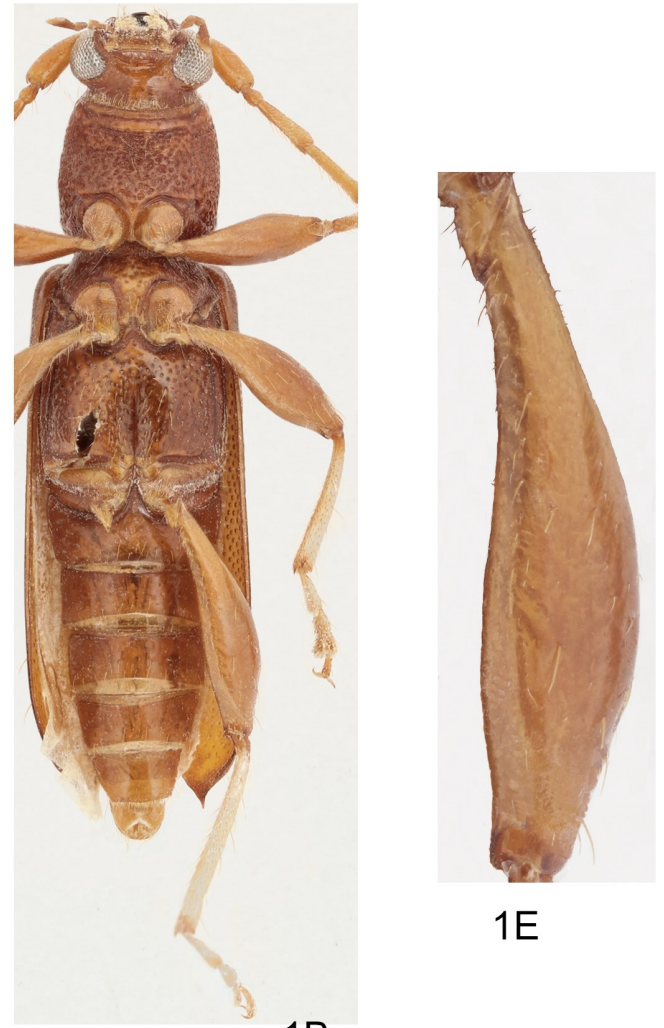

$1 \mathrm{E}$

1B

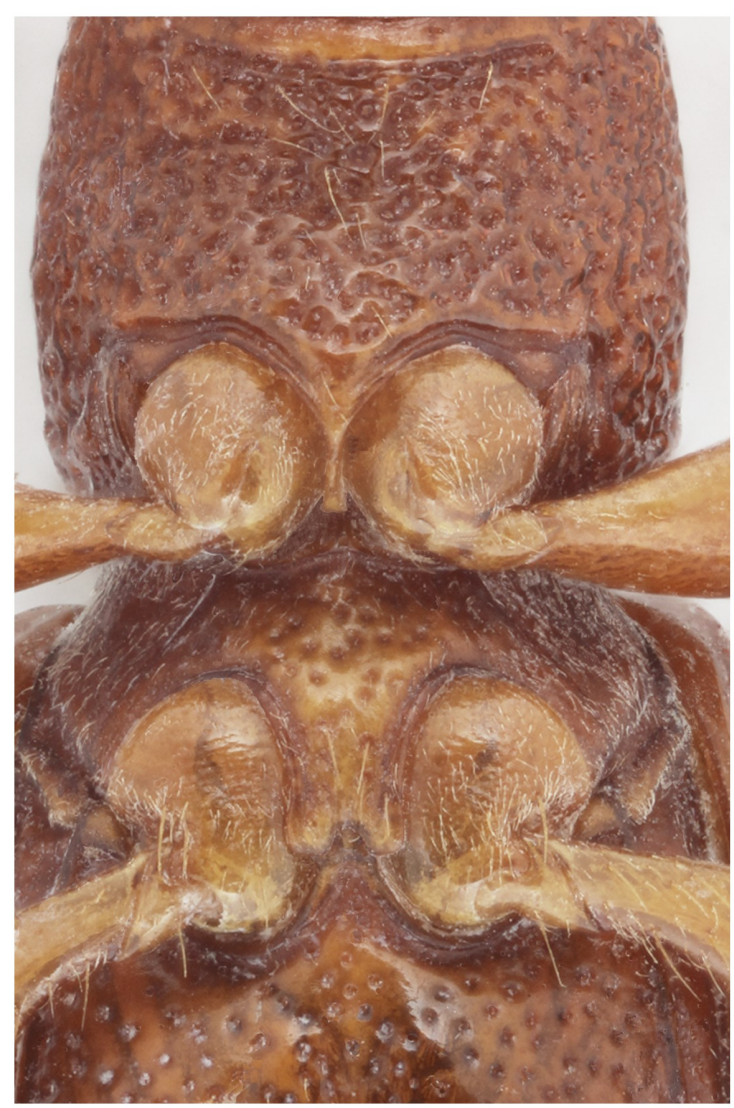

$1 \mathrm{D}$

Figures 1A-E. Tethionea peggieae sp. nov. Holotype male. 1A, habitus, dorsal view; 1B, ditto, ventral view; $1 \mathrm{C}$, head and pronotum, latero-dorsal view; $1 \mathrm{D}$, thorax, ventral view; $1 \mathrm{E}$, hind femur. 


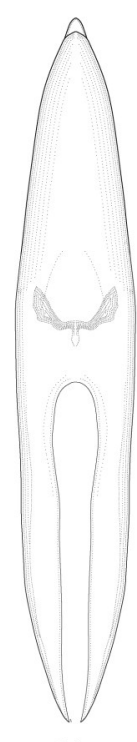

$2 \mathrm{~A}$

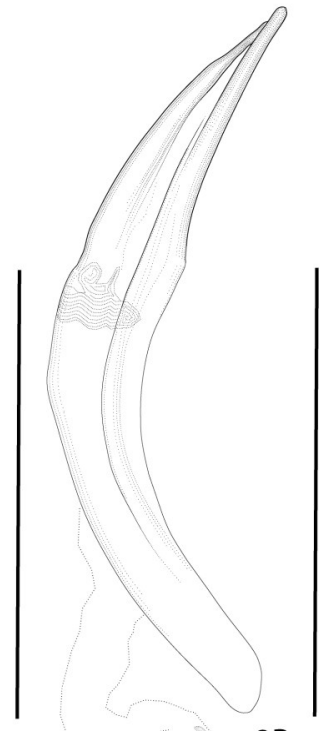

$2 \mathrm{~B}$

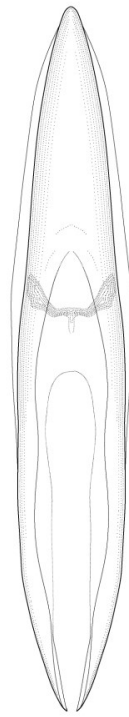

$2 \mathrm{C}$

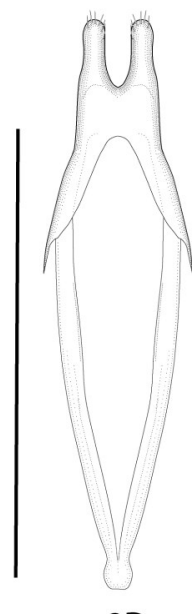

$2 \mathrm{D}$

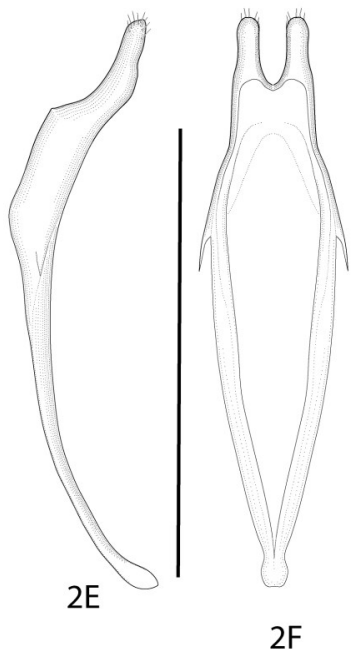

$2 \mathrm{~F}$
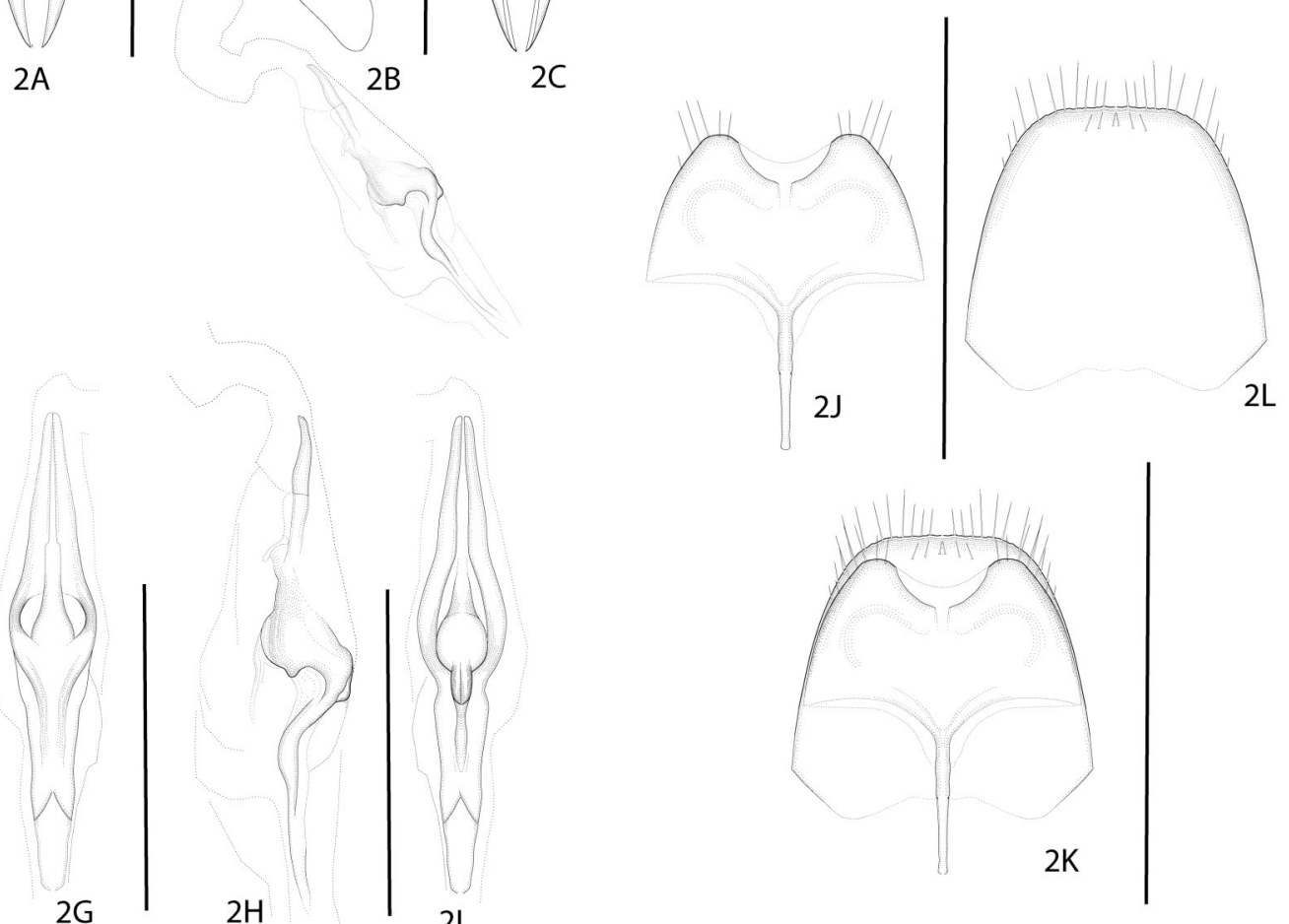

21

Figures 2A-L. Tethionea peggieae sp. nov. Holotype male. Genitalia. 2A, median lobe, dorsal view; 2B, ditto, lateral, with endophallus; $2 \mathrm{C}$, ditto, ventral; $2 \mathrm{D}$, tegmen, dorsal view; $2 \mathrm{E}$, ditto, lateral; $2 \mathrm{~F}$, ditto, ventral; 2G, endophallus, ejaculatory duct complex, dorsal view; $2 \mathrm{H}$, ditto, lateral; $2 \mathrm{I}$, ditto, ventral; $2 \mathrm{~J}, 8^{\text {th }}$ sternite, ventral view; $2 \mathrm{~K}$, ditto, with $8^{\text {th }}$ tergite in the background; $2 \mathrm{~L}, 8^{\text {th }}$ tergite, ventral view. Scale bar: $0.5 \mathrm{~mm}$ for $2 \mathrm{G}-\mathrm{I}$; $1 \mathrm{~mm}$ for the others.

Comparative notes. The new species can be distinguished externally by the pronotum. It is elongated, with sides uneven, densely, deeply punctate-verrucose. In addition, the upper eyelobes are more widely separated from each other than usual. Tethionea waigeona Gressitt shares uniform body color and singly acuminose elytral apices with the new species. However, its pronotum is less strongly elongated and simply punctate on sides. The genitalia of the new species, including the ejaculatory duct complex, are essentially similar to those of already examined species of genera Ceresium, Stenodryas, Examnes and Oxymagis. 
Tethionea unicolor Pascoe, 1869

(Figs 3A-E; 4A-L)

Tethionea unicolor Pascoe, 1869: 543. Type locality: “Aru”.

Tethionea unicolor: Gemminger \& Harold, 1872: 2838.

Tethionea unicolor: Aurivillius, 1912: 126.

Tethionea unicolor: Gressitt, 1951: 20.

Tethionea unicolor: Gressitt, 1959: 120, 121.

Tethionea unicolor: Slipiński \& Escalona, 2016: 299

Material examined. ơ: “Gogol River, Madan, PNG, 10-20. iii. 1986, H. Makihara leg.

\section{Additional description.}

(Head, pronotum, elytra and legs as in the original description)

Terminal joints of maxillary palpi truncated and opened on both sides (Figs 11C-E).

Venter. Prosternum transverse; sides rounded; the middle widely, horizontally impressed; setae sparse, fine, short, recumbent; apical 1/3 nitid, strigate; otherwise deeply punctate, partly rugose. Prosternal process well-bordered, narrow, constricted between the coxae; apex expanded, sub-truncated, impressed in the middle. Mesoventrite with sparse though large, deep punctures; setae short and sparse; moderately elevated toward the process. Mesoventral process sub-parallel-sided; apex moderately emarginated in the middle. Metaventrite transverse-sub-rectangular, convex, glossy, regularly provided with setiferous punctures each bearing a short recumbent hair.

Abdomen glossy, with sparse setiferous punctures; gradually narrowed toward apex; sternites 4-6 about half as long as the third; $7^{\text {th }}$ about $2 / 3$ as long.

Male genitalia as Figs 3E; 4A-L. Median lobe about 2/5 the length of abdomen, bulletshaped in dorsal view, narrow and weakly arcuate in lateral view; dorsal plate dehiscent in basal 7/10; ventral plate nearly as long, dehiscent in basal 4/5. Tegmen about 7/10 the length of median lobe, stout, feebly arcuate in lateral view. Parameres about half the length of tegmen, gradually tapering toward apex; apical 1/5 bi-lobed; each lobe with several stout apical setae. Ejaculatory duct complex as Figs 4G-I; about 3/10 as long as median lobe, stout, composed of three inter-connected sclerites; apical sclerite spatulate in dorsal view, thick; median sclerite stout, sub-toroidal in dorsal view, with a horn-shaped projection; basal sclerite elongated-spatulate, apically dehiscent. $8^{\text {th }}$ sternite cotyledonary in outline; blade transverse, sub-emarginated on apex, a little thinned in the middle, fringed with several long apical setae, supplemented by shorter hairs in the apical middle; peduncle 3/4 as long as blade. $8^{\text {th }}$ tergite sub-trapezoidal, broader than the sternite, moderately emarginated on apex; the latero-apical corners rounded; apical setae similar as those of the sternite. $7^{\text {th }}$ tergite trapezoidal, much larger than $8^{\text {th }}$ tergite; apex weakly arcuate.

Distribution. Aru, Northern Queensland, Papua New Guinea (New Distribution). 
Comparative notes. Compared to the holotype from Aru, no obvious difference in morphology was observed. The genitalia, including the ejaculatory duct complex, are essentially analogous to those of Tethionea peggieae sp. nov. With the new record of this species from Papua New Guinea, its distribution has become continuous between Aru and Queensland.
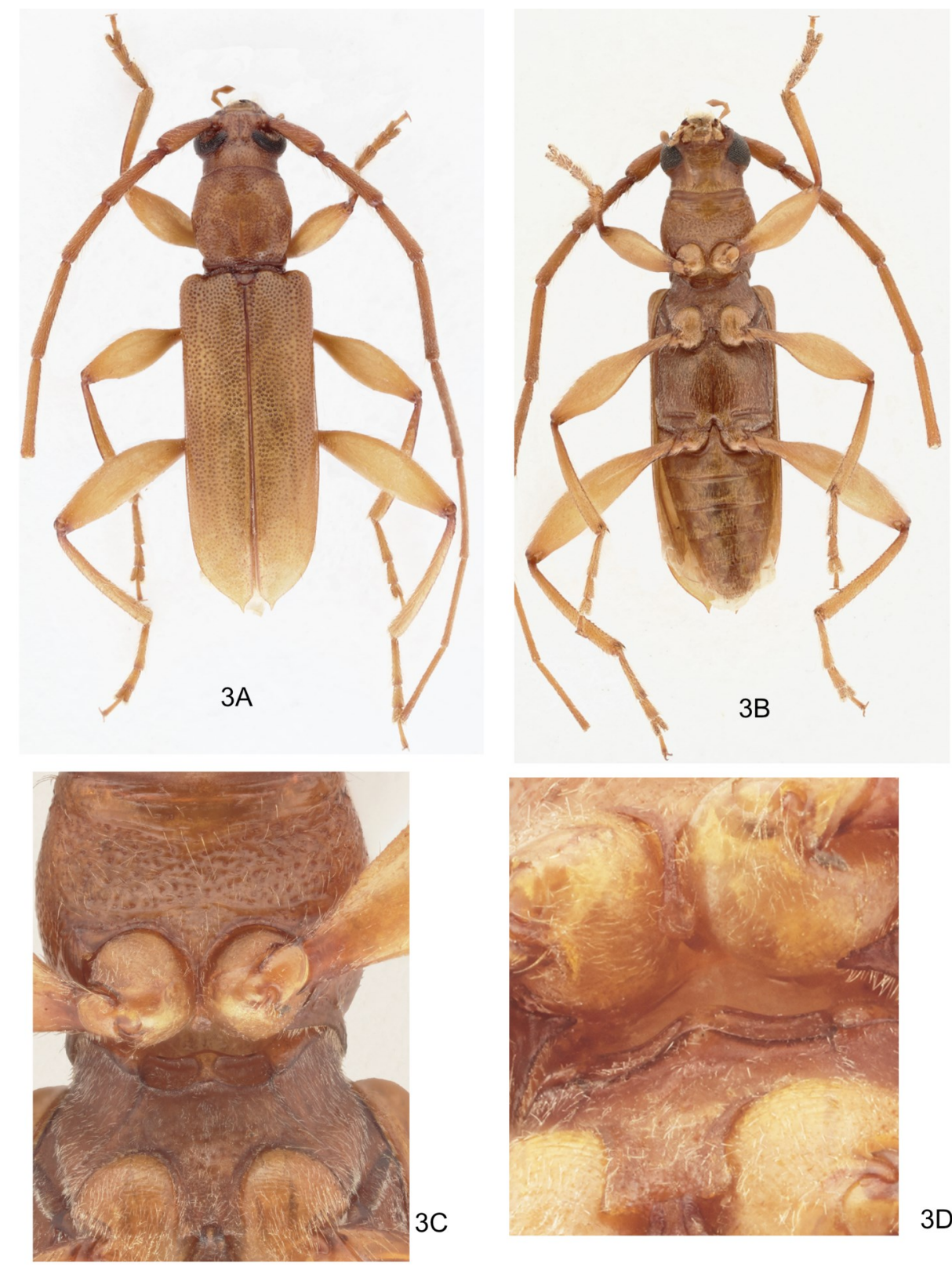

$3 \mathrm{D}$

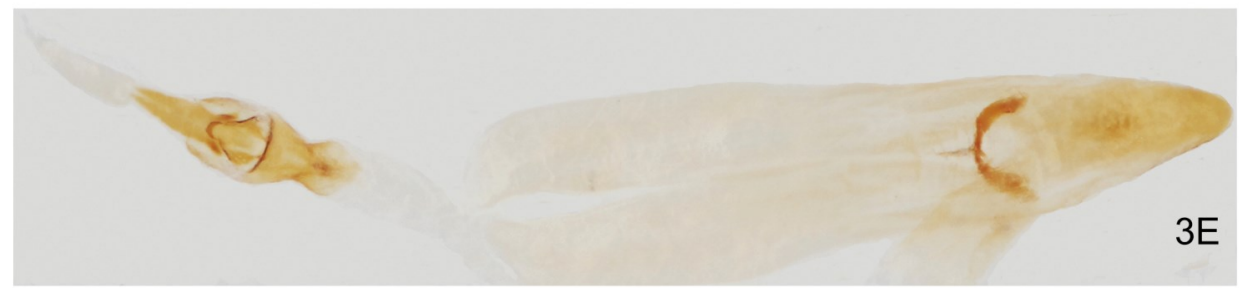

Figures 3A-E. Tethionea unicolor Pascoe. Male from Papua New Guinea. 3A, habitus, dorsal view; 3B, ditto, ventral; $3 \mathrm{C}$, prosternum and mesoventrite; 3D, prosternal and mesoventral processes, ventral view, angled; $3 \mathrm{E}$, median lobe and endophallus with ejaculatory duct complex, ventral view. 

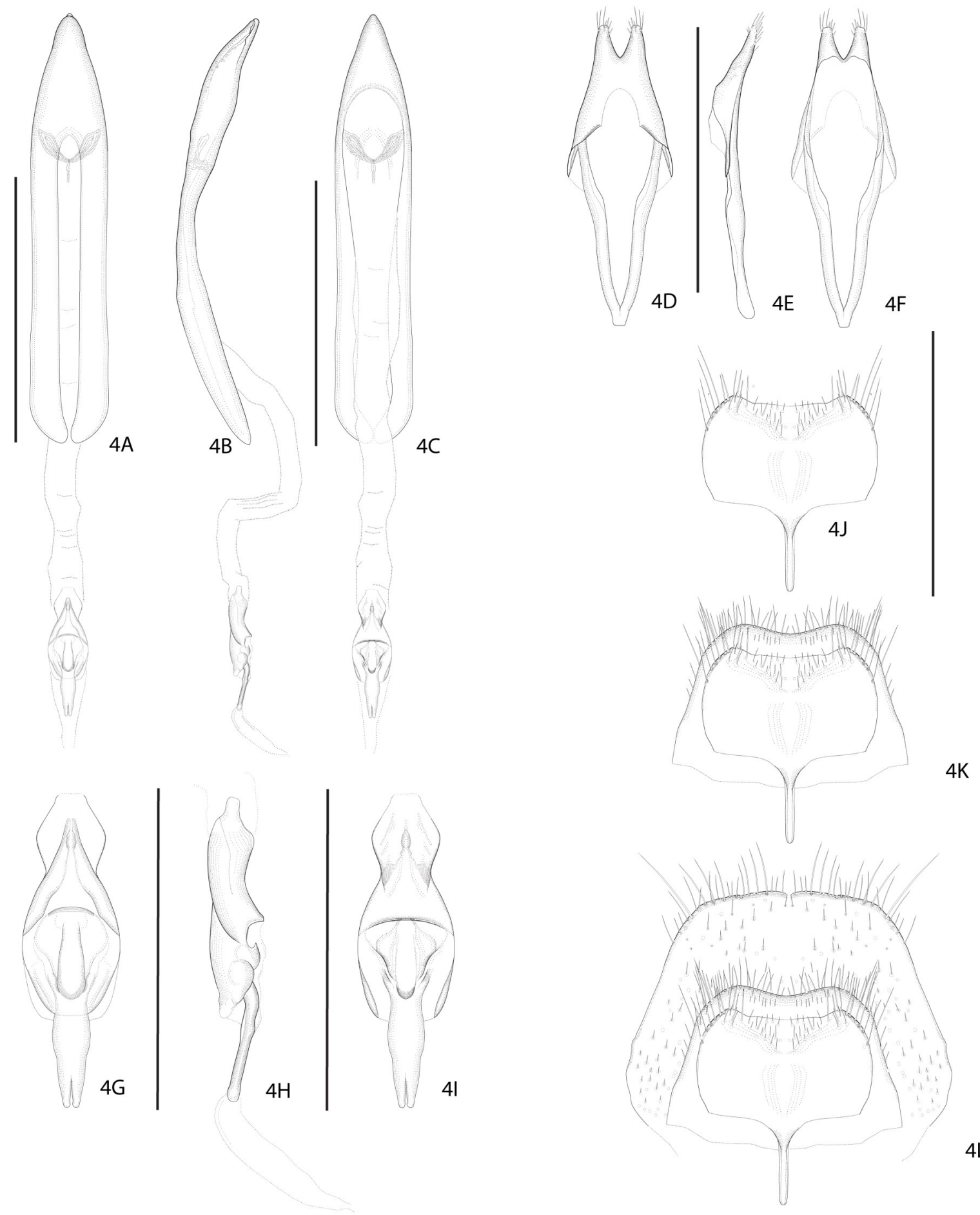

Figures 4A-L. Tethionea unicolor Pascoe. Male from Papua New Guinea. Genitalia. 4A, median lobe with endophallus, dorsal view; 4B, ditto, lateral view; 4C, ditto, ventral; 4D, tegmen, dorsal view; 4E, ditto, lateral; 4F, ditto, ventral; $4 \mathrm{G}$, endophallus, ejaculatory duct complex, dorsal view; $4 \mathrm{H}$, ditto, lateral; 4I, ditto, ventral; $4 \mathrm{~J}, 8^{\text {th }}$ sternite, ventral view; $4 \mathrm{~K}$, ditto, with $8^{\text {th }}$ tergite in the background; $4 \mathrm{~L}$, ditto, with $7^{\text {th }}$ tergite in the background. Scale bar: $0.5 \mathrm{~mm}$ for $4 \mathrm{G}-\mathrm{I} ; 1 \mathrm{~mm}$ for the others. 
Tethionea strumosa Pascoe, 1869

(Figs 5A-C; 6A-K)

Tethionea strumosa Pascoe, 1869: 544. Type locality: Ceram, Amboyna.

Tethionea strumosa: Gemminger \& Harold, 1872: 2838.

Tethionea strumosa: Macleay, 1886: 202.

Tethionea strumosa: Aurivillius, 1912: 126.

Tethionea strumosa: Gressitt, 1951: 18, 19.

Tethionea strumosa: Gressitt, 1959: 190, 121.

Material examined. $\widehat{\delta}$ : "INDONESIA; Irian Jaya, Freeport Concession, Timika. 18-25. VIII. 1997, R. Ubaidillah, Peggie" 97026". "Lowland r. forest, Kuala Kencana Light Ind. Park, 4. 2621' S. 136.5259' W. 100 m. Malaise trap 2 (Site 5)". “575”.

\section{Additional description.}

(Head, pronotum, elytra and legs as in the original description)

The terminal joint of maxillary palp as in the original description (Fig. 11A).

Venter. Prosternum transverse, widely impressed in the middle, concave in profile; surface irregularly punctate, partly rugose-strigate; with an arcuate horizontal furrow stretching from side to side at apical 1/3; setae sparse, short, fine, recumbent. Prosternal process similar as of T. unicolor, though less strongly constricted. Mesoventrite sparsely, shallowly punctured; setae finer than on prosternum; the middle moderately elevated toward the process. Mesoventral process broad; the apical part sub-parallel-sided, twice vertically impressed. Metaventrite transverse-sub-rectangular, rounded; with regular, setiferous punctures each bearing a short recumbent hair.

Abdomen glossy; sparsely provided with small, shallow, setiferous punctures; setae short and recumbent; sternites 4-7 gradually reducing in length and width.

Male genitalia as Figs 6A-K. Median lobe more than 2/5 the length of abdomen, bulletshaped in dorsal view, arcuate in lateral view; dorsal plate dehiscent in basal 11/20; ventral plate longer, dehiscent in basal 4/5. Tegmen about $9 / 10$ the length of median lobe, rather narrow in dorsal view, weakly arcuate in lateral view. Parameres about 9/20 the length of tegmen, gradually tapering toward apex; apical 1/4 bi-lobed; each lobe with several stout apical setae. Ejaculatory duct complex as Figs 6G-I; more than $1 / 3$ the length of median lobe; composed of four inter-connected sclerites; apical sclerite slender, sub-annular in dorsal view, attached by a sclerotized appendage, which is slender, sharply bent downward and apically bi-lobed; median sclerite bifurcated, with a prominent, horn-shaped dorsal projection; basal sclerite composed of a pair of narrow, elongated flagella. 8th sternite cotyledonary in outline; blade rounded at the corners, strongly thinned in the middle, fringed with several long apical setae, supplemented by shorter ones in the apical middle; peduncle 
about half the length of the blade. $8^{\text {th }}$ tergite sub-trapezoidal with rounded corners, moderately emarginated on apex; apical half nearly as broad as the sternite; with several long setae along the apical margin.

Distribution. Seram, Ambon, Waigeo, Papua Province (Indonesia); Fly River, New Britain, Goodenough (Papua New Guinea).

Comparative notes. Compared to the holotype from Maluku, no obvious difference in morphology was observed. The genitalia of T. strumosa are essentially analogous to those of the above two species. The ejaculatory duct complex is, however, one of the most intricate and delicate among the examined species. $8^{\text {th }}$ tergite of this species resembles that of the above described Tethionea unicolor.

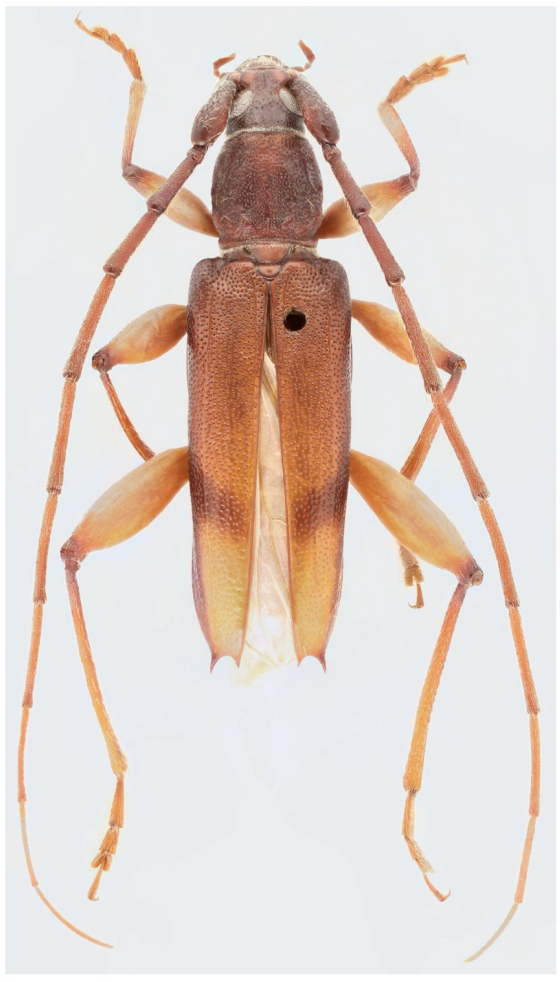

$5 A$

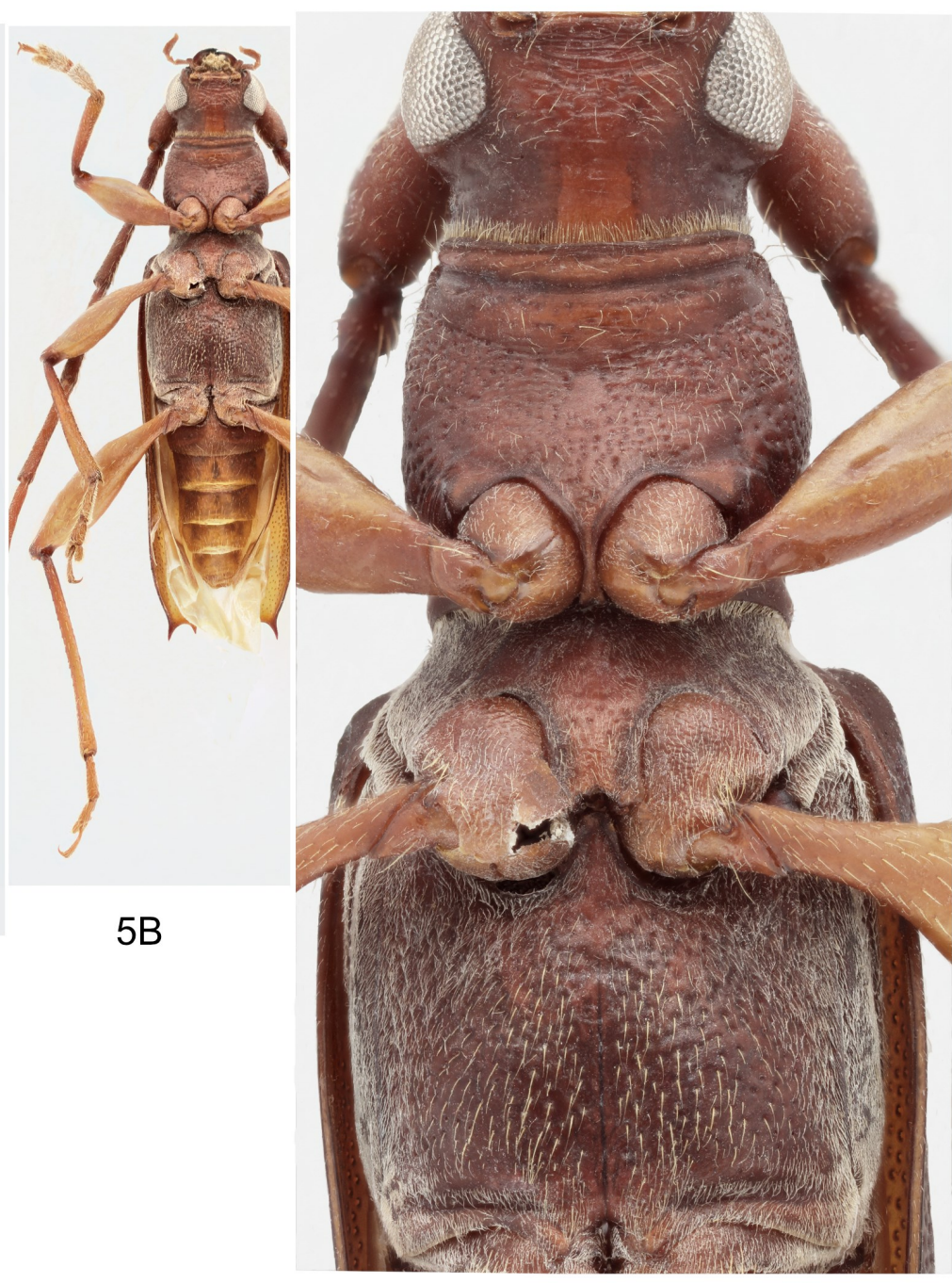

$5 \mathrm{C}$

Figures 5A-C. Tethionea strumosa Pascoe. Male from Papua New Guinea. 5A, habitus, dorsal view; 5B, ditto, ventral view; 5C, head and thorax, ventral view. 


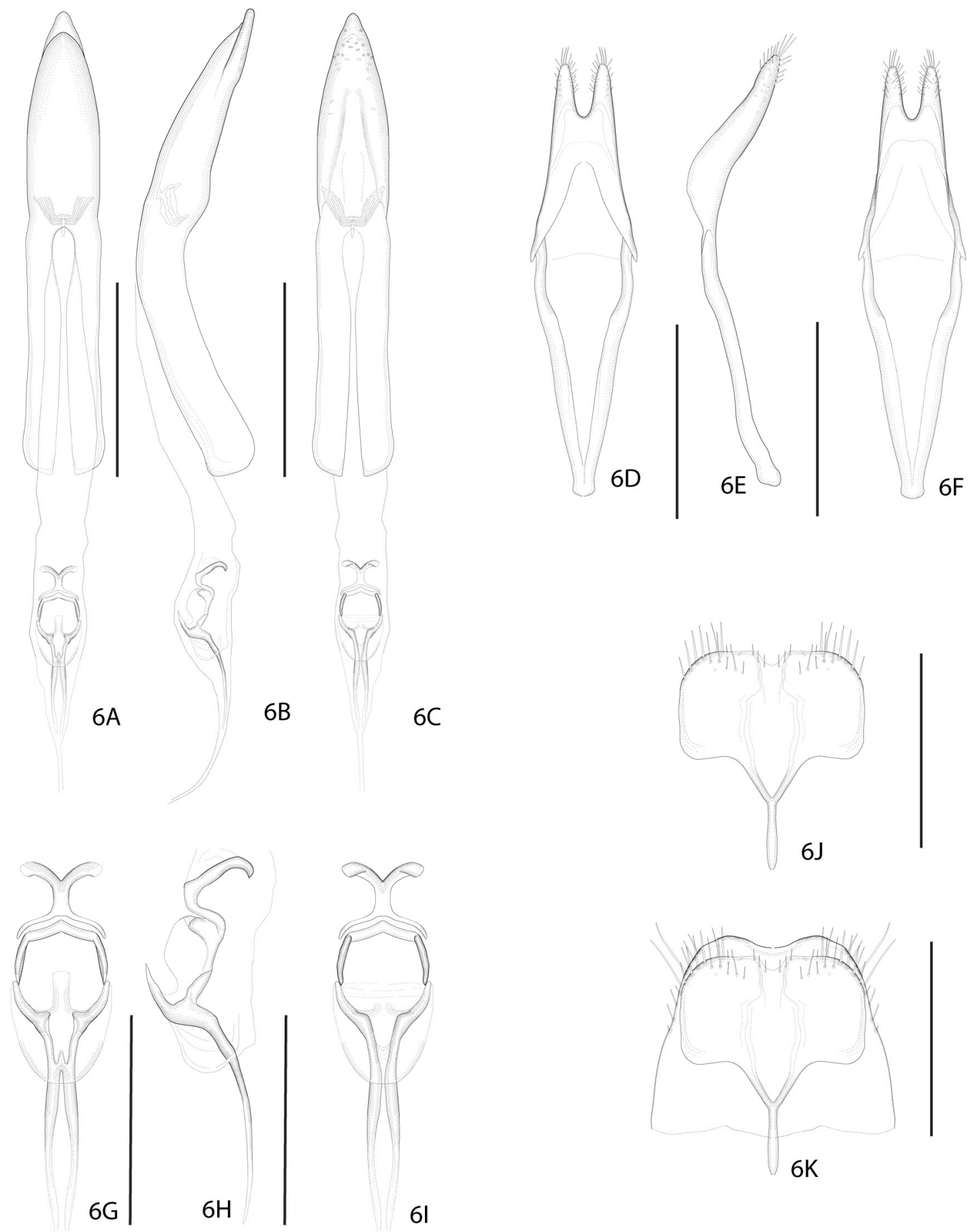

Figures 6A-K. Tethionea strumosa Pascoe. Male from Papua New Guinea. Genitalia. 6A, median lobe with endophallus, dorsal view; 6B, ditto, lateral view; 6C, ditto, ventral view; 6D, tegmen, dorsal view; 6E, ditto, lateral view; $6 \mathrm{~F}$, ditto, ventral view; $6 \mathrm{G}$, endophallus, ejaculatory duct complex, dorsal view; $6 \mathrm{H}$, ditto, lateral view; $6 \mathrm{I}$, ditto, ventral view; $6 \mathrm{~J}, 8^{\text {th }}$ sternite, ventral view; $6 \mathrm{~K}$, ditto, with $8^{\text {th }}$ tergite in the background. Scale bar: $0.5 \mathrm{~mm}$ for $6 \mathrm{G}-\mathrm{I}$; $1 \mathrm{~mm}$ for the others. 
Tethionea tridentata Pascoe, 1869

(Figs 7A-D; 8A-M)

Tethionea tridentata Pascoe,1869: 545. Type locality: Batchian.

Tethionea tridentata: Gemminger \& Harold, 1872: 2838.

Tethionea tridentata: Aurivillius, 1912: 126.

Tethionea tridentata: Mckeown, 1947: 48.

Tethionea tridentata: Gressitt, 1951: 19.

Tethionea tridentata: Gressitt, 1959: 119, 121.

Tethionea tridentata: Vives, Aberlenc \& Sudre, 2008: 140 ; fig. 2b.

Tethionea tridentata: Ślipiński \& Escalona, 2016: 299.

Material examined. ơ: “Gogol River, Madan, PNG, 10-20.iii.1986, H. Makihara leg.

\section{Additional description.}

(Head, pronotum, elytra and legs as in the original description)

The terminal joint of maxillary palp as in the original description. (Fig. 11B).

Venter. Prosternum similar as of $T$. unicolor, though the middle more sparsely punctaterugose; prosternal process similar. Mesoventrite with the process also similar. Metaventrite transverse, feebly dilated toward apex, well convex, glossy, regularly punctate; punctures setiferous near middle; setae short and recumbent.

Abdomen glossy; with sparse, small, shallow, setiferous punctures; several setae thereof curved, longer than the others. Sternites 4-7 gradually reducing in length and width.

Male genitalia as Figs 7D; 8A-M. Median lobe nearly 9/20 the length of abdomen, bulletshaped in dorsal view, arcuate in lateral view; dorsal plate dehiscent in basal $2 / 3$; ventral plate longer, dehiscent in basal 7/9. Tegmen about 8/9 the length of median lobe, rather narrow in dorsal view, arcuate in ventral view. Parameres about $2 / 5$ the length of tegmen, gradually tapering toward apex; apical $1 / 4$ bi-lobed; each lobe with several stout apical setae. Ejaculatory duct complex as Figs 7D; 8G-I; more than 1/3 the length of median lobe; composed of three inter-connected sclerites; apical sclerite in dorsal view spatulate-subtriangular with base emarginated, arcuate in lateral view; median sclerite stout, with a hornshaped projection; basal sclerite elongated-spatulate, apically expanded and deeply dehiscent. Blade of 8th sternite hexagonal; apical half trapezoidal; basal half parallel-sided; base thinned; apex fringed with several stout setae; supplemented by several short ones near the middle; peduncle about half the length of blade. $8^{\text {th }}$ tergite sub-circular, as broad as the sternite at base, connected to the sternite with a thick membranous structure (Fig. 8L). $7^{\text {th }}$ tergite trapezoidal, much larger than the $8^{\text {th }}$ tergite, fringed with a line of apical hairs.

Distribution. Bacan, Waigeo, Yapen (Indonesia); Madang, New Britain (Papua New Guinea); Malaita, Vanikoro (Solomon Is.); Queensland (Australia). 
Comparative notes. Compared to the holotype from Maluku, no obvious difference in morphology was observed. The genitalia of the new species resemble those of the above observed species. However, its $8^{\text {th }}$ sternite is remarkable. In particular, the blade is projected forward to form an unusual trapezoidal outline. The peduncle is exceptionally short in comparison to the blade. This type of $8^{\text {th }}$ sternite has been so far observed neither in the genus nor in the related genera.

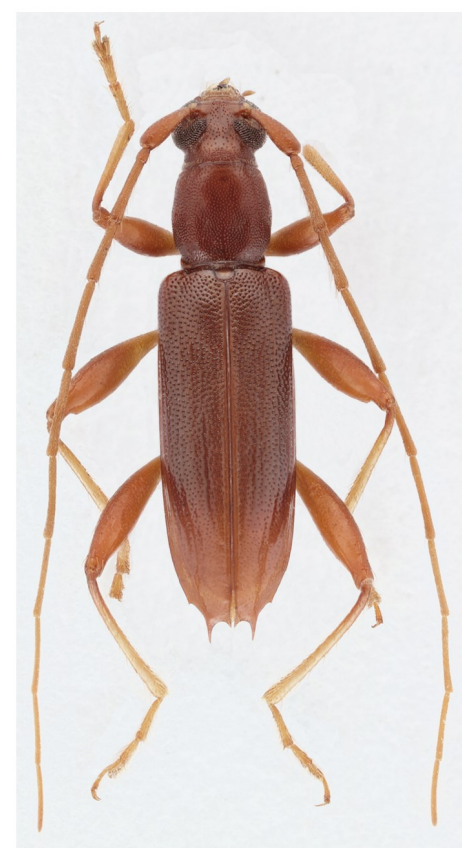

$7 \mathrm{~A}$

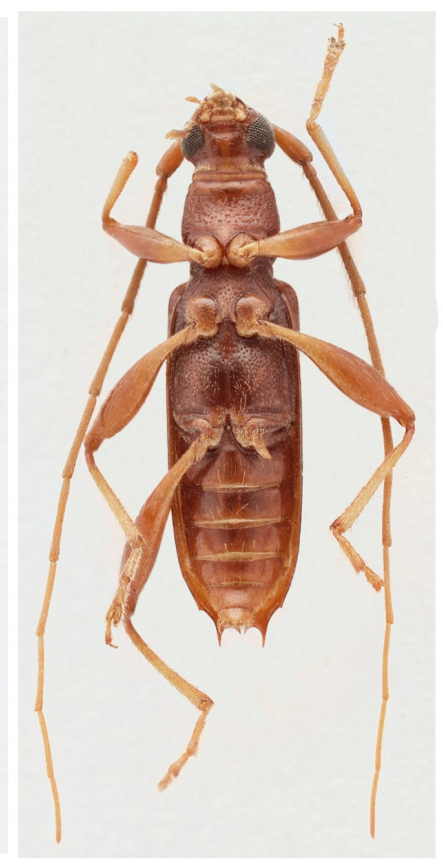

$7 \mathrm{~B}$
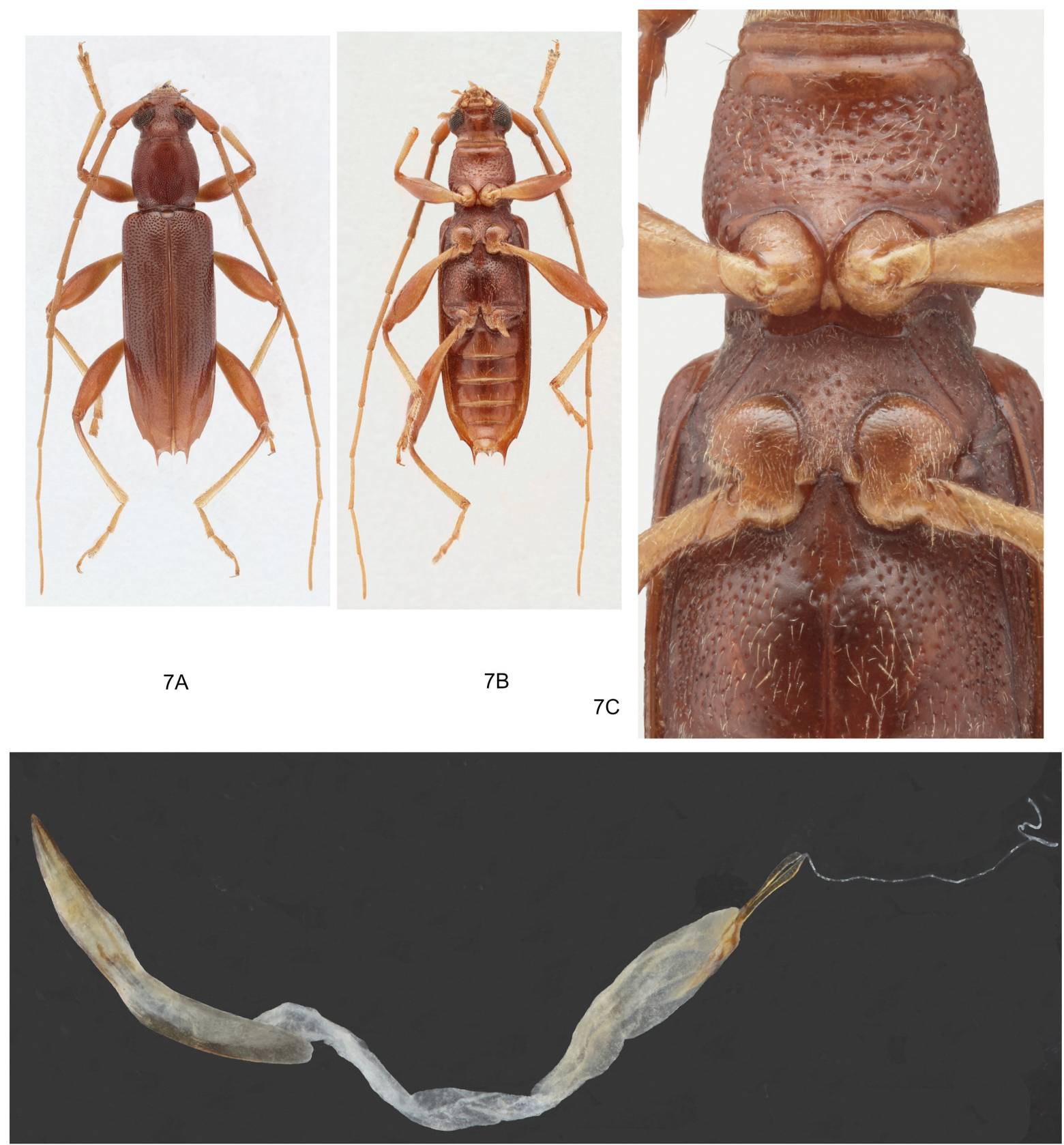

$7 D$

Figures 7A-D. Tethionea tridentata Pascoe. Male from Papua New Guinea. 7A, habitus, dorsal view; 7B, ditto, ventral view; 7C, thorax, ventral view; 7D, median lobe and endophallus with ejaculatory duct complex, lateral view. 

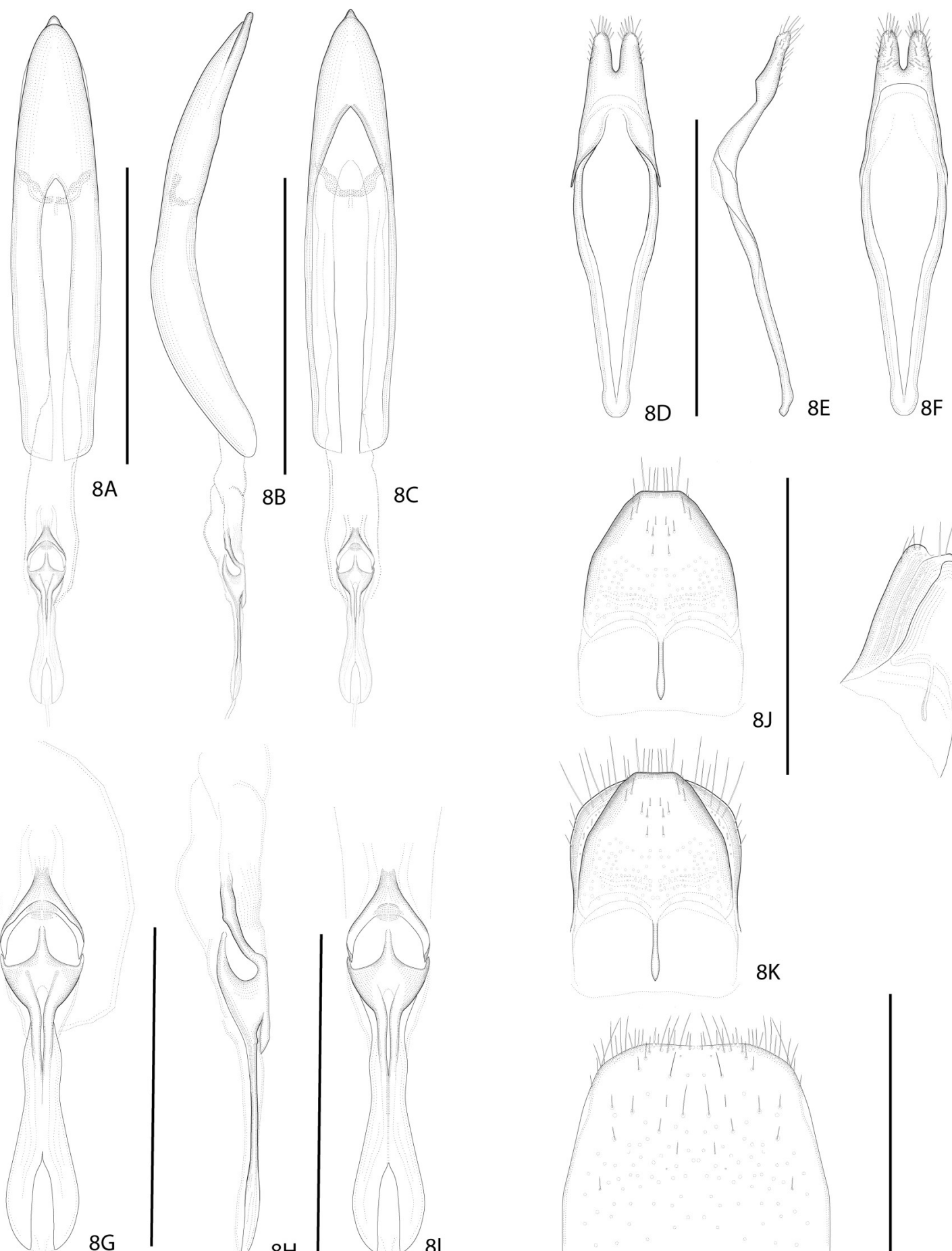

$8 \mathrm{~B}$

$8 \mathrm{C}$

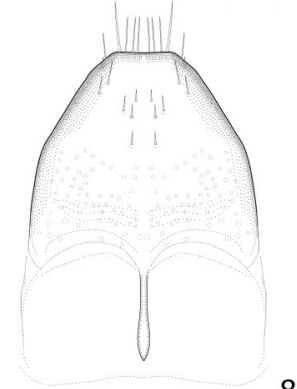

8J

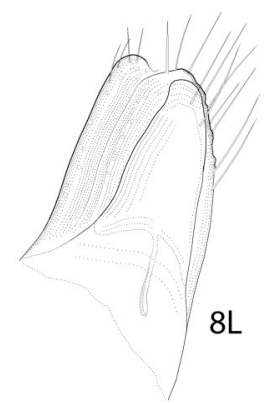

$8 \mathrm{G}$
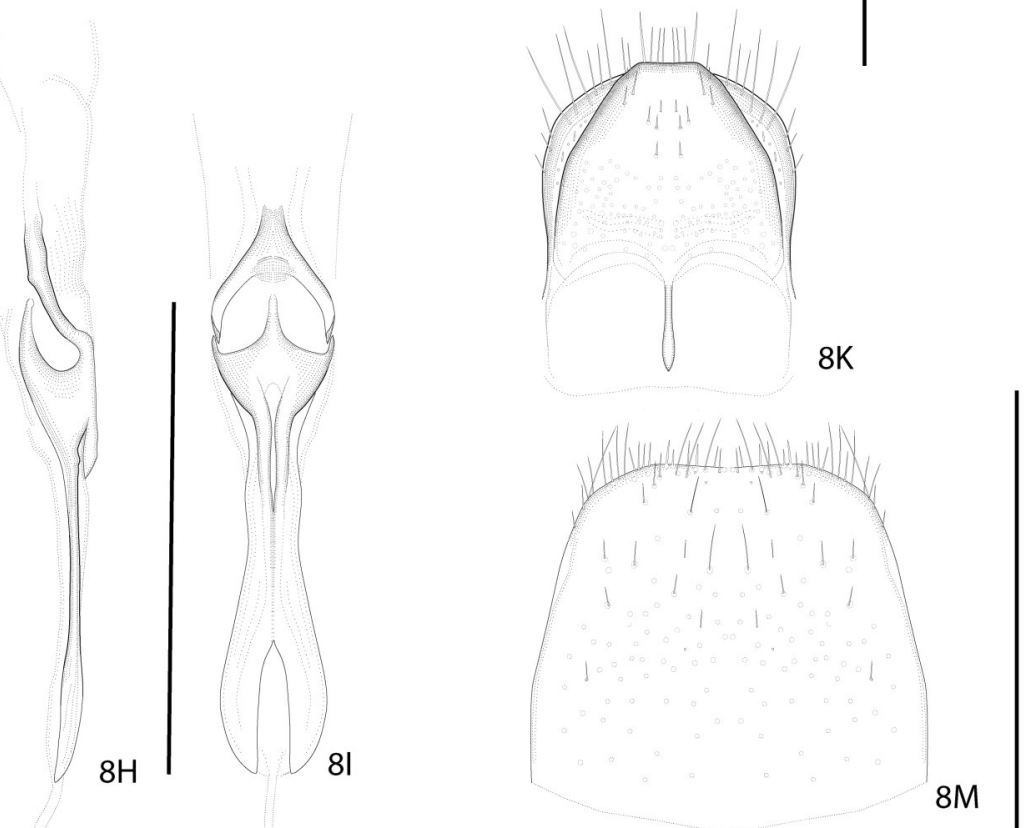

Figures 8A-M. Tethionea tridentata Pascoe. Male from Papua New Guinea. Genitalia. 8A, median lobe with endophallus, dorsal view; $8 \mathrm{~B}$, ditto, lateral; $8 \mathrm{C}$, ditto, ventral; 8D, tegmen, dorsal view; $8 \mathrm{E}$, ditto lateral view; $8 \mathrm{~F}$, ditto, ventral; $8 \mathrm{G}$, endophallus, ejaculatory duct complex, dorsal view; $8 \mathrm{H}$, ditto, lateral; $8 \mathrm{I}$, ditto, ventral; $8 \mathrm{~J}, 8^{\text {th }}$ sternite, ventral view; $8 \mathrm{~K}$, ditto, with $8^{\text {th }}$ tergite in the background; $8 \mathrm{~L}$, ditto, latero-dorsal view, angled; $8 \mathrm{M}, 7^{\text {th }}$ tergite, dorsal view. Scale bar: $0.5 \mathrm{~mm}$ for $8 \mathrm{G}-\mathrm{I}$; $1 \mathrm{~mm}$ for the others. 
Tethionea oculata sp. nov.

(Figs 9A-E; 10A-H)

Material examined. Holotype $\odot:$ "INDONESIA, Irian Jaya, Freeport Concession Timika, 12-19. IX. 1997, R. Ubaidillah, Peggie 97032"; "Lowland r. forest, Kuala Kencana Light Ind. Park, 4. 2621' S. 136.5259' W. 100 m. Malaise trap 2 (Site 5)”; “336”. Paratype O: "Pandans peat swamp, East levee of Minajerwi River, 4. 4099'S. 136.5854'W. 15 m. Malaise trap-1 (Site 4)"; “7702”.

Diagnosis. Testaceous; glossy. Eyes large; much more approximate to each other than usual. Pronotum elongated, regularly punctate. Prosternal process strongly constricted and terminated between pro-coxae. Elytral apices each terminated with an acuminate spine; the sutural side sub-linear.

Etymology. The name of this new species refers to its large eyes.

\section{Description.}

Measurements. Ble=10.0-8.2mm. EL/EW=3.0-2.85. HW/PW=1.0. PL/PW=1.12. PA/ $\mathrm{PW}=0.72-0.7$. $\mathrm{PB} / \mathrm{PW}=0.8$. (First figure for the holotype, when two figures given).

Color testaceus; antennae and legs a little paler; setae yellowish.

Head as Figs 9C-E. Glossy, glabrous. Occiput, vertex and upper half of frons regularly, deeply, though sparsely punctured. Frons deeply emarginated on sides by lower eye-lobes; with a median groove. The terminal joint of maxillary palp spatulate, with the external side moderately truncated and opened. Vertex broad, widely flattened, feebly concave in the middle. Eyes large; upper eye-lobes separated from each other by $3 / 2$ the width of apical lobe or less than 3/10 the width of occiput. Antennal supports flattened. Antennae nearly reaching the elytral apices. Scapes weakly clavate and arcuate; each with a few large setiferous punctures. Antennomeres 3, 4, 5, 6 each 19/20, 9/10, 12/10, 11/10 as long as scape; 7-11 a little shorter.

Pronotum longer than broad, almost hairless, glossy, regularly and densely punctured; apex and base moderately constricted. Sides evenly arcuate; surface uneven with a few irregular protuberances. Disc with a nitid median stripe half the length of pronotum. Scutellum bell-shaped, strongly bordered.

Elytra moderately long; sides sub-parallel-sided in basal 4/5; apices each terminated with an acuminous spine; the sutural side of the spine sub-linear or feebly emarginated. Each elytron regularly, densely punctured; with several erect, stout hairs toward apex.

Legs rather long and slender. Femora moderately clavate from base on; a little flattened.

Venter. Prosternum glossy; concave in profile, horizontally impressed in the middle; deeply, coarsely punctate-rugose there, with several fine hairs. Prosternal process apically 

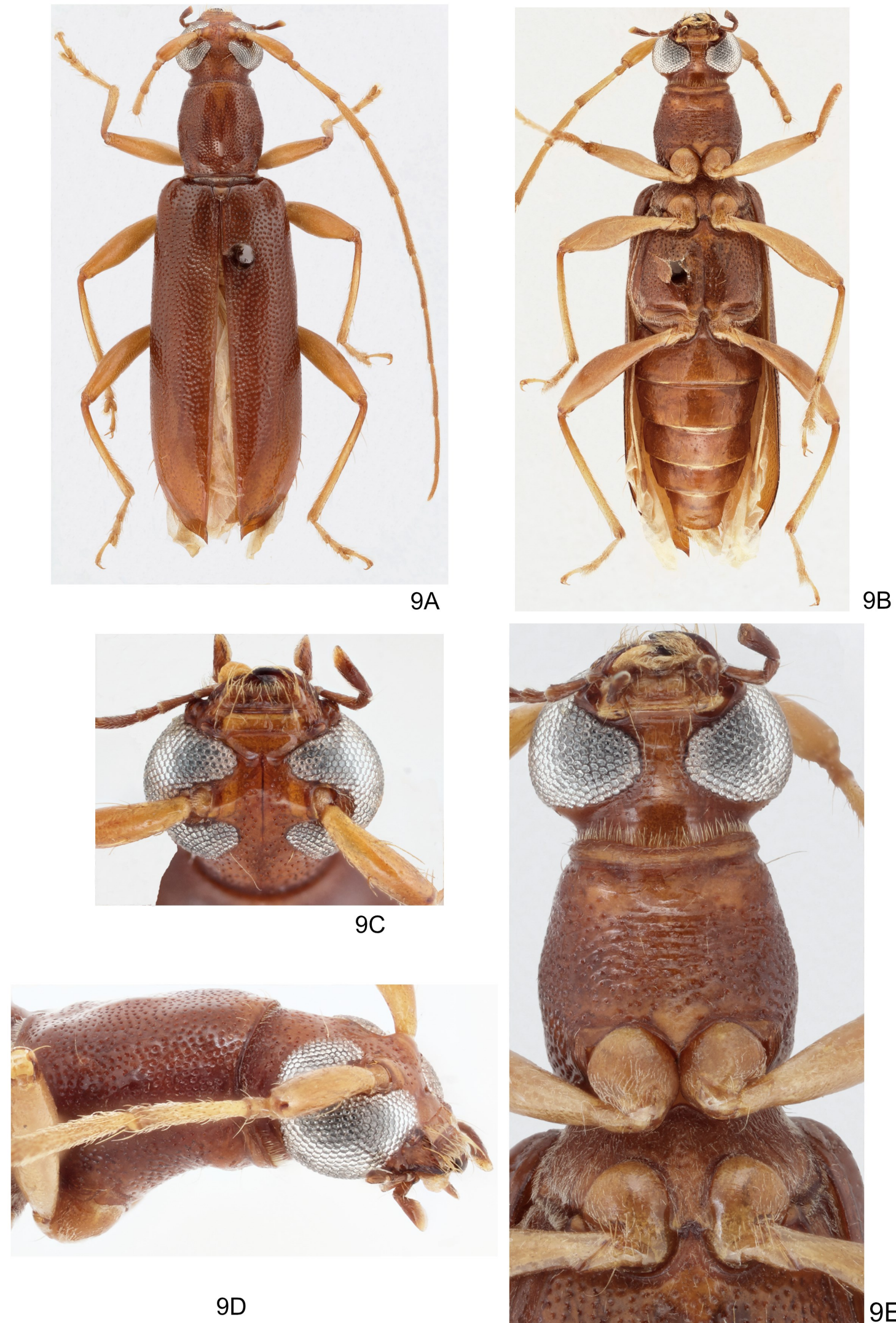

Figures 9A-E. Tethionea oculata sp. nov. Holotype female. 9A, habitus, dorsal view; 9B, ditto, ventral view; 9C, head; 9D, head and pronotum, lateral view; 9E, head and thorax, ventral view. 
reduced, acutely terminated between procoxae. Mesoventrite similar to that of T. strumosa. Mesoventral process also similar, though a little narrower. Metaventrite transverse-subrectangular, well rounded; glossy, with large, regular though sparse punctures, which are more or less setiferous in the middle.

Abdomen glossy; with sparse setiferous punctures; sternites 4-6 gradually reducing in length and width. $7^{\text {th }}$ sternite sub-trapezoidal, distinctly longer than the $6^{\text {th }} .7^{\text {th }}$ tergite subcircular, fringed with short apical setae (Fig. 10C).

Female genitalia as Figs 10A-H. Blade of $8^{\text {th }}$ sternite sub-trapezoidal, longer than broad; apical part prolonged with a membranous structure; clothed with several medium-sized stout hairs on an arcuate horizontal line at apical $1 / 5$; peduncle about $5 / 2$ as long as blade. $8^{\text {th }}$ tergite with latero-basal corners produced and moderately acute. $9^{\text {th }}$ sternite rather short; coxite a little shorter than paraproct; styli stout, each with several short hairs. Vaginal plates elongated, arcuate-flagellar. Bursa copulatrix oval. Spermatheca kidney-shaped, connected to apical vagina with a long duct.

Distribution. Papua Province (Indonesia).

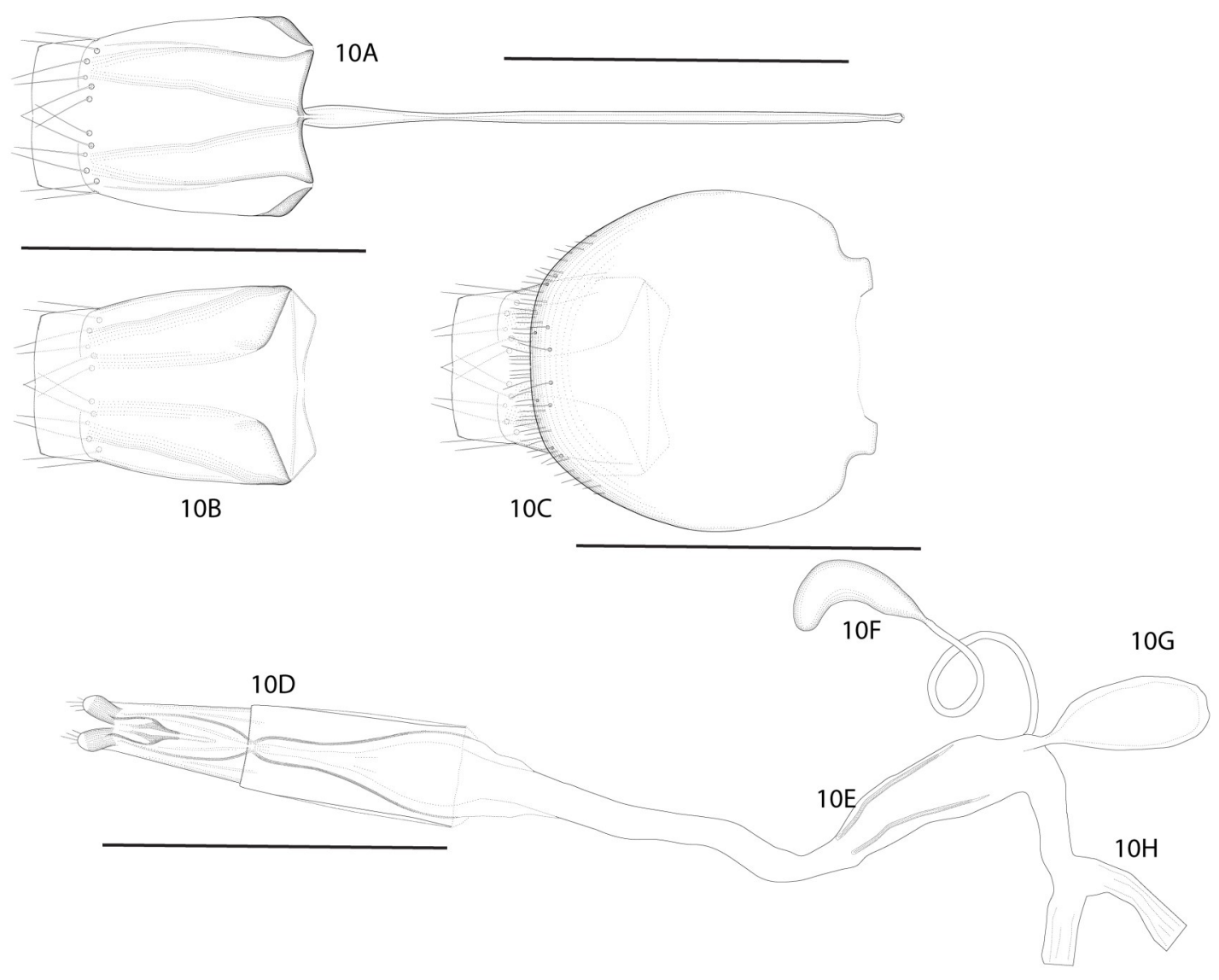

Figures 10A-H. Tethionea oculata sp. nov. Holotype female. Genitalia.10A, $8^{\text {th }}$ sternite, ventral view; 10B, $8^{\text {th }}$ tergite, ventral view; $10 \mathrm{C}, 7^{\text {th }}$ tergite with $8^{\text {th }}$ tergite in the background, dorsal view; $10 \mathrm{D}, 9^{\text {th }}$ sternite; $10 \mathrm{E}$, vaginal plates; 10F, spermatheca; 10G, bursa copulatrix; 10H, median oviduct. Scale bar: $1 \mathrm{~mm}$. 
Comparative notes. Tethionea oculata sp. nov. can be distinguished by its large eyes, which are much more approximate to each other than usual. In addition, its prosternal process is terminated instead of expanded toward apex. In other respects, it is most comparable to Tethionea waigeona Gressitt, 1955, and Tethionea tenuimembris Gressitt, 1951.

\section{DISCUSSION}

Male genitalia of Tethionea species. Endophalli of altogether four species, T. peggieae sp. nov., T. unicolor, T. strumosa and T. tridentata were investigated for this publication. In each of these species, the characteristic apical sclerotization, referred to as "ejaculatory duct complex", was identified. Tethionea is thus the fifth genus of the tribe observed with this type of endophallus, after Ceresium, Examnes, Stenodryas and Oxymagis (Yokoi, 2019; 2021a; 2021b; 2022 in press; Yokoi et al., 2019). The ejaculatory duct complexes of the examined Tethionea species are relatively large, $3 / 10$ to $1 / 2$ as long as median lobe, whereas their structures are among the most intricate of the examined genera. Regarding the other genital organs, no essential difference from the above four genera was observed.

The $8^{\text {th }}$ sternites of the examined male species are mostly broad and stout. In three species, $T$. peggieae sp. nov., T. strumosa and T. tridentata, they are as broad as or nearly as broad as the $8^{\text {th }}$ tergite. $8^{\text {th }}$ sternite of $T$. tridentata differs markedly from these species. The elongated hexagonal outline with extremely short peduncle is unusual even as a species of the Callidiopini.

Maxillary palpi. In the original descriptions of $T$. strumosa and T. tridentata, both male, Pascoe observed that the terminal joints of their maxillary palpi are "rather singular", "the truncate slope commencing nearly from base, so that the greater part of the joints appear to be removed" (Pascoe, 1869). This observation is now confirmed for these two species, as described and illustrated above (Figs 11A-B). In this regard, it should be noted that a third species, Tethionea unicolor, is also distinct, though in a different way; the terminal joints of its maxillary palpi are truncated on both sides (Figs $11 \mathrm{C}-\mathrm{E}$ ). Tethionea peggieae sp. nov. is also distinct. The terminal joints of its palpi are simply and moderately truncated (Fig. 11F), but this type of maxillary palp is rather commonly observed in various genera of the tribe. The type of maxillary palpi observed by Pascoe is not shared by all the members of Tethionea. His hypothesis that "it is very probably characteristic of the genus" is not confirmed.

Later, Gressitt (1955) presented a comprehensive illustration of maxillary palpi, and described, in particular, those of Tethionea bidentata Gressitt, Tethionea bicolor Gressitt 
and Tethionea waigeona Gressitt, all male, concluding that the genus is characterized, among others, by "last maxillary palpal segment with one or two cavities". This statement is essentially valid for the hitherto examined species, so long as furrows, openings and truncated sections are interpreted as various forms of cavities.

Regarding the female apical palp, Pascoe noted that it is "cylindrical or only slightly triangular". Tethionea oculata sp. nov. does not correspond to this observation, as the joint is obviously truncated, though only moderately (Fig. 11G).

Prosternal processes. The structure of prosternal processes is variable among the five examined species of Tethionea. The process is obviously expanded toward apex in $T$. unicolor, T. tridentata and T. strumosa, while moderately so in T. peggieae sp. nov. In contrast, it is terminated between the procoxae in $T$. oculata. This observation does not correspond to the description by Ślipiński and Escalona (2016). Additional species should be observed for a valid general statement.

Tethionea oculata sp. nov. In a few respects, this species is singular among the examined Tethionea species. Its eyes are exceptionally large. Their upper lobes are more approximate to each other than usual. The same is valid for the lower eye-lobes. Further, its prosternal process is terminated between pro-coxae, in contrast to those of the other species. The male genitalia of this species should be investigated.

Prospect. Besides the above T. oculata sp. nov., several other Tethionea species are atypical. T. pubescens Gressitt, T. squamata Gressitt, T. subcallosa Gressitt, all three from New Guinea, each with unusual integument, are such examples. T. brevicollis Gressitt from New Guinea and Tethionea minima Vives from the Philippines differ in the structure of head and pronotum. Further, antennae and legs of Tehionea bicincta Fauvel from New Caledonia are distinct. These species should be examined as to their positions in the genus. Moreover, some species of other genera resemble Tethionea species in a way or another, particularly of Semiope Pascoe,1869, from New Guinea and of Notoceresium Blackburn, 1901, from Australia and New Guinea. Of the widely distributed Ceresium, its subgenus Ceresium (Ceresiellum ) Gressitt, 1956, from Micronesia and Fiji, should be examined regarding its affinity to Tethionea.

Male genitalia of these species, essential keys for their taxonomy, should be carefully examined. Regrettably, many pivotal species are still not available to the authors. Contributions by colleagues are welcome. 


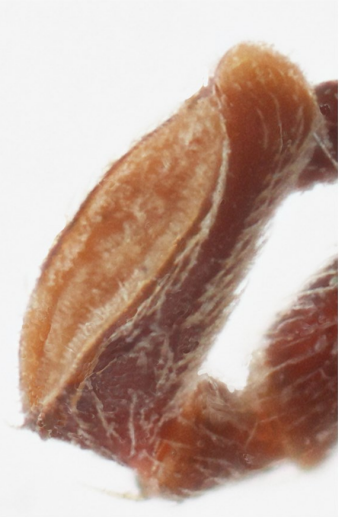

$11 \mathrm{~A}$

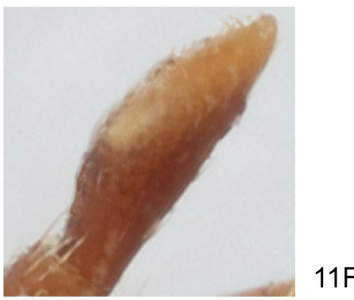

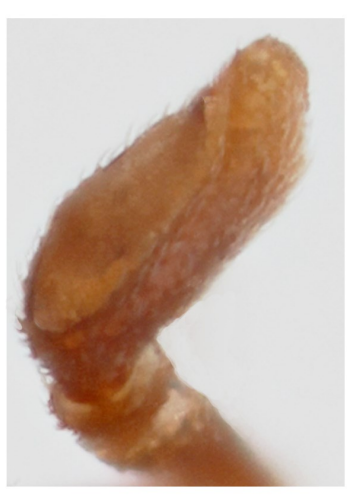

11B

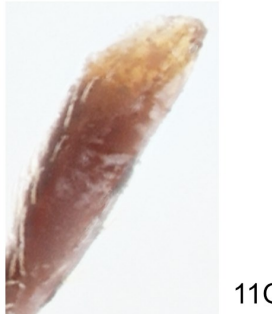

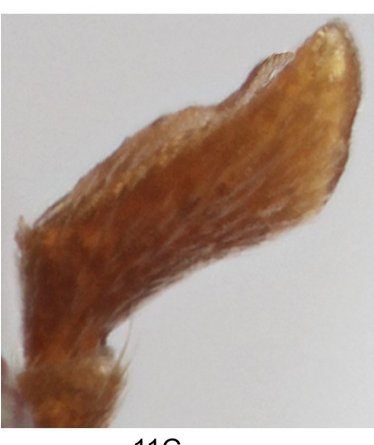
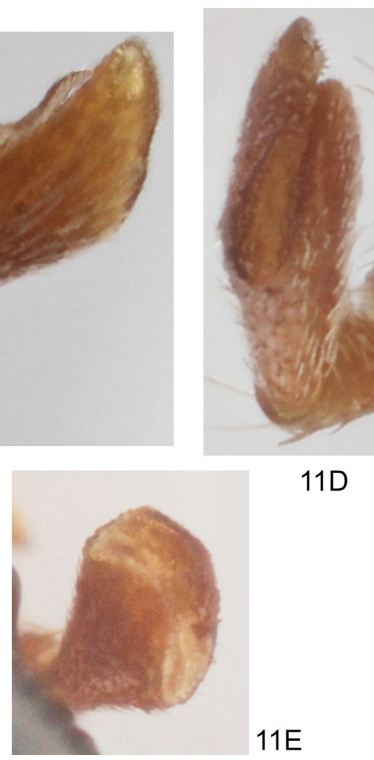

$11 \mathrm{G}$

Figures 11A-G. Tethionea species. Terminal joint of maxillary palp. 11A, T. strumosa (male); 11B, T. tridentata (male); 11C, T. unicolor (male); 11D, ditto, external side; 11E, ditto, apical view; 11F. T. peggieae sp. nov. (male); 11G, T. oculata sp. nov. (female).

\section{ACKNOWLEDGMENTS}

We would like to thank Dr. Djunijanti Peggie, butterfly curator of the Entomology Lab in the Museum Zoologicum Bogoriense, for providing us with the material preserved in the collection of the MZB. Our research was based on this material. We wish to thank Kartika Dewi, Ph.D. (Research Center for Biology-BRIN) for her assistance in editorial aspects of the publication. We wish to thank Mr. Sarino, technical officer of the Entomology Lab, for the preparation of the material, which greatly facilitated our research project. We wish to thank Dr. Sugiarto of East Kutai Agricultural Scientific College, Indonesia, for his assistance and contribution during the field works in Indonesia. We are grateful to Mr. Maxwell V. L. Barclay of the Natural History Museum, London, for enabling us to examine relevant holotypes preserved there. We thank professor Nobuo Ohbayashi, Kanagawa, Japan, for useful information and discussion on important taxonomical aspects. Last but not least, we would like to thank Karin de Wit-Yokoi, wife of the first author, for proof-reading.

\section{REFERENCES}

Aurivillius, C. 1912. Cerambycidae: Cerambycinae. Coleopterum Catalogus Pars 39 (vol. 22), Berlin: $1-574$.

Fauvel, C.A.L. 1906. Faune analytique des Coléopterès de la Nouvelle-Calédonie, 4 partie. Revue d'Entomologie. Caen, 25: 29-100. 
Gemminger, M. \& Harold, E. 1872. Catalogus coleopterorum hucusque synonymicus et systematicus. Monachii, Sumptu E. H. Gummi (G. Beck) 9: 2668-2988.

Gressitt, J.L. 1951. Longicorn beetles from New Guinea and the South Pacific (Coleoptera: Cerambycidae). Part I. Annals of the Entomological Society of America, 44(1): 1-30, $1 \mathrm{pl}$.

Gressitt, J.L. 1955. The longicorn genus Tethionea (Coleoptera: Cerambycidae). Proceedings of the Hawaian Entomological Society, 15(3): 411-417, 21 figs.

Gressitt, J.L. 1956. Coleoptera: Cerambycidae. Insects of Micronesia, 17(2): 61-183, 33 figs.

Gressitt, J.L. 1959. Longicorn beetles from New Guinea I (Cerambycidae). Pacific Insects, 1(1): 59171.

Hayashi, M. 1979 Study on Cerambycidae from West Malaysia (Col.) Part II. Bulletin of the Osaka Jonan Women's Junior College 13: 51-87.

Holzschuh, C. 2015. Beschreibung von XX neuen Bockkäfern aus Südostasien (Coleoptera, Cerambycidae). Les Cahiers Magellanes (NS), 20: 14-75, 51 figs.

Macleay, W.J. 1886. The Insects of the Fly River, New Guinea, "Coleoptera." The Proceedings of the Linnean Society of New South Wales ( $2^{\text {nd }}$ series), 1: 183-204.

McKeown, K. C. 1947. Catalogue of the Cerambycidae (Coleoptera) of Australia. Memoirs of the Australian Museum, 10: 1-190.

Pascoe, F.P. 1862. Notices of new or little-known genera and species of Coleoptera. Part III. Journal of Entomology, London, 1 (5) 26: 319-370, pls XVI-XVII.

Pascoe, F.P. 1869. Longicornia Malayana; or a descriptive catalogue of the species of the three longicorn families Lamiidae, Cerambycidae and Prionidae, collected by Mr. A. R. Wallace in the Malay Archipelago. Transaction of Entomological Society, London, 3(3): 535-542, pl. 21.

Ślipiński, A. \& Escalona, E.S. 2016. Australian Longhorn Beetles (Coleoptera: Cerambycidae) Volume 2, Subfamily Cerambycinae. Australia: Melbourne: CSIRO Publishing: 1-613.

Vives, E. 2015. New or interesting Cerambycidae from the Philippines (Part X) (Coleoptera, Cerambycidae, Cerambycinae). Les Cahiers Magellanes (NS), 18: 1-18, 15 figs.

Vives, E. 2016. New or interesting Cerambycidae from the Philippines (Coleoptera, Cerambycidae, Cerambycinae). (Pars XIV). Lambillionea, 116(3): 182-187, 3 figs.

Vives, E., Aberlenc, H.P. \& Sudre, J. 2008. Entomofauna de Vanikoro (Islas Salomon). 4a. contribution: Coleoptera: Cerambycidae. Heteropterus Revista de Entomologia, 8(2): 137-146, 2 figs.

Yokoi, Y. 2015. Notes on the Callidiopini (Coleoptera, Cerambycidae) across the Lombok Strait. Elytra (n. ser.), 5: 185-205.

Yokoi, Y. 2019. Callidiopini beetles in the collection of Zoologische Staatssammlung München (ZSM) Part I. SPIXIANA, 42(1): 19-46.

Yokoi, Y. 2021a. Taxonomic notes on the tribe Callidiopini Lacordaire, 1869 (Coleoptera: Cerambycidae) and some other taxa of the Papuan Region, mainly from the Solomon Islands, with descriptions of five new species. Biodiversity, biography and nature conservation in Wallacea and New Guinea Volume IV. Riga: 363-396.

Yokoi, Y. 2021b. Notes on the taxonomy and genitalia of eight Cerambycinae (Coleoptera: Cerambycidae) species from the collection of the Royal Belgian Institute of Natural Sciences, with description of two new species and one new subspecies. Bulletin S.R.B.E/ K.B.V.E.1.157 (2021): 64-91.

Yokoi, Y., Makihara, H. \& Noerdjito, W.A. 2016. Note on the Genera Examnes and Pelossus (Coleoptera, Cerambycidae) in East Kalimantan, Indonesia. Elytra (n. ser.), (2): 229-246.

Yokoi, Y., Makihara, H. \& Noerdjito, W.A. 2019. Callidiopini beetles (Coleoptera, Cerambycidae) in the collection of Indonesian Institute of Sciences (LIPI). Treubia, 46(1): 1-20. 